\title{
ALGUNAS CONSIDERACIONES ACERCA DE LOS NOM- BRES DE DIOS EN EL ISLAM. BENEFICIOS QUE PROCURA EL USO DE LOS MISMOS
}

\author{
José VALDIVIA VÁLOR ${ }^{1}$ \\ Universidad de Alicante
}

Explican los Maestros Suffes que cuando sentimos la necesidad de un acercamiento a Dios existe en la persona el sentido de obligación, wazifa, palabra técnica usada en árabe y en persa para "repetición" o "ejercicio". El sentido de obligación que conlleva el término supone obligación hacia mi Creador.

El maestro da al discípulo una serie de instrumentos o medios con los cuales éste va identificándose y desarrollando su percepción.

Junto con la oración una de las técnicas más valiosas es el dikr, frase o palabra, que el discípulo debe repetir un número de veces de manera que llegue no sólo a tomar conciencia sino además a producir un tipo de energía que supone un valor incalculable.

${ }^{1}$ Es para mi un honor y un placer el participar en este homenaje a la Profesora, querida amiga y compañera, Dra. Rubiera, "María Jesús" como entrañablemente la llamamos los amigos, y no sólo por su muy meritoria labor de investigación científica sino también por su labor docente y sus desvelos por nuestro Departamento, por el arabismo, por la Universidad de Alicante, y, en definitiva, por la Universidad. Con todo cariño trataré este pequeño estudio acerca de los Nombres de Dios, especialmente en algunos autores de la tradición islámica, sin olvidar el legado y contribución que la tradición judeocristiana le aporta, $y$ viceversa.

Gracias al actual ecumenismo y a la claridad con que sabios y estudiosos de nuestro tiempo vienen exponiendo la trascendencia del tema en el hombre de hoy, ya sean eruditos o gentes sencillas, la necesidad del acercamiento a Dios prende con fuerza en el corazón y en la mente de los hombres. 
Esta energía será almacenada y producirá el efecto requerido a su debido tiempo, es decir, cuando sea necesaria. Se produce de modo diferente la energía, el movimiento y la armonía de una actividad según se realice el $\underline{d i k r}$ de forma individual o junto a otras personas.

$$
* * *
$$

En el Antiguo Testamento aparece ya el nombre de Dios como El Innombrable, El Inefable; por ello ha llegado a considerarse de mayor valía el silencio que la palabra.

Conocemos en hebreo el significado del verbo "ser"; mediante él se manifiesta la palabra Dios, Yahvé, presente, pasado y futuro del verbo ser: El que es, ha sido y será.

Tenemos precedentes de los nombres de Dios en los campos de la teología y la mística islámicas en los autores cristianos más antiguos. Este interés por el conocimiento de la manifestación de Dios por medio de sus atributos se encuentra desde los primeros tiempos del Cristianismo. En el Capítulo I de "Los Nombres de Dios" del Pseudo Dionisio el Areopagita ya el presbitero Dionisio se dirige al copresbitero Timoteo notificándole el propósito de su tratado y cual sea la tradición de los nombres de Dios. En él precisa, además, que para explicar los nombres divinos se atendrá a la norma observada en los textos sagrados (I, Cor. 2 ,4) de manera que cuando presentemos la verdad de la palabra de Dios "no sea con persuasivos discursos de humana sabiduría sino en la manifestación del poder del Espíritu" dado a los escritores sagrados. Dice acerca de Dios que es aquella Infinita Supraesencia que trasciende toda esencia, aquella Unidad que está más allá de toda inteligencia.... Él es el Ser y ningún ser es como Él. Es obvio el paralelismo con lo que habria de ser posteriormente el fundamento de la fe islámica. He aquí en síntesis la primera y principal coincidencia del concepto islámico con el cristiano.

Son numerosísimas, además, las coincidencias de los atributos de Dios vistos por teólogos y místicos del Islam, de igual modo que lo consideran los autores cristianos. Dice el Areopagita acerca de Dios que es La Bondad Universal, causa de todo ser. Le llama Luz, Fuente, Vida, Esencia, Principio, y Causa. Contemplamos - dice- la Luz divina que nos dispone para alabar la Fuente donde mana abundante toda 
iluminación santa. La Fuente que nos habla de Sf misma con palabras de las Santas Escrituras, Vida de los vivientes, Esencia de los seres, Principio y Causa, por su bondad, de toda vida y esencia. Por su misma bondad produce y mantiene en su ser todas las cosas. Él es antes que todo y todo subsiste en Él.

Además de estos atributos posee Dios la Sabiduría, el Poder, la Justicia, la Salvación, la Redención, la Desigualdad. Dios es el Grande, la Grandeza, el Omnipotente, la Paz, el Santo de los santos; es el Rey de reyes, el Dios de dioses, el Perfecto y el Uno².

Tanto en el Islam como en el Cristianismo se considera que una parte de los atributos divinos se manifiesta en el ser humano, del cual el mayor merecedor será aquél que haya alcanzado el máximo grado de perfección.

Daniel Gimaret, en su tratado de los Nombres de Dios, en donde traza las líneas generales del estudio de los Nombres de Dios, que tanto ha llamado la atención a islamólogos así como a estudiosos del cristianismo, hace mención de los diversos apelativos de Jesús aplicados en el Nuevo Testamento, de los cuales menciona como notorio los 187 nombres que figuran en la antología griega de finales del siglo VII publicada por Fr. Diekamp, bajo el título "Doctrina Patrum de Incarnatione Verbi" $y$, aunque por costumbre, no se hayan hecho compilaciones de listas en general, de todas maneras siempre -como él mismo indica- han sido más usuales entre los cristianos las letanías en honor a la Virgen María ${ }^{3}$. No obstante, existe un abundante material dentro del campo de la lírica popular, y también en poetas y místicos, dedicado tanto a María como a Jesús y a Muhammad, en donde se les menciona con los más amables apelativos ${ }^{4}$.

${ }^{2}$ Cfr. Psendo Dionisio Areopagita, Los nombres de Dios, Obras Completas, B.A.C. Madrid, 1990, pp. 269-368.

${ }^{3}$ Daniel Gimaret, Les Noms Divins en Islam, Les éditions du Cerf, Paris, 1988.

${ }^{4}$ Vid. en villancicos, obras de Lope de Vega, Fray Luis de León, San Juan de la Cruz y tantos otros. En cuanto al profeta Muhammad, uno de los más famosos panegíricos en honor de su nacimiento, es el mevlid en lengua turca de Süleyman Celebi. Estos mevlid, o mawlid en árabe, nacimiento, son abundantes tanto en árabe como en turco y suelen recitarse en la fiesta que conmemora el 
Conocida es hoy -y para ello mucho debemos a la labor investigadora de D. Miguel Asín- la influencia que el Islam recibe del Cristianismo y a su vez la que éste recibe de aquél. Asf́ Ramón Llull -que se confiesa suff cristiano, como advierte el maestro Ribera- utiliza como atributos de Dios casi la misma terminologia que los autores islámicos.

Allah/Deus; Ar Rahmānn/O Graciant; Ar Rahīm/O Misericordiant; Al Malik/O Rey; Al Quddus/O Sant; Al Jāliq/O Creador; Al Mu'izz/O Onrat; As Samī' /O Exoïdor; Al 'Adl/O Justicia; Al 'Azīim/O Infinitat; Al 'Aliyy/O Alt; Al Kabīr/O Gran; Al Muqīt/O Sustenidor; Al Karīm/O Larguea; Al Muṣawwir/O Forma; Al Wāsi'/O Tot; Al Maŷ̃d/O Gloria; Al Bā'it_/O Resucitador.

También Fray Luis de León, de la orden de San Agustín, al tratar de los nombres de Dios en general aplica a Dios, como a su vez hicieran los autores musulmanes, los atributos de Sabiduría, Justicia Infinita, Misericordia, Poder, Saber y Amor. En Él -dice- todo es Uno, idéntico concepto al de la ciencia y la mística islámicas.

Con la extremada precisión que le caracteriza, matiza, como los místicos del Islam, la importancia en la palabra del sonido, la figura, el origen y el significado de los nombres. Dice textualmente: "si el nombre substituye por lo nombrado, y si su fin es hacer que lo ausente que significa, en él nos sea presente, y cercano y junto lo que nos es alejado, mucho conviene que en el sonido, en la figura, o verdaderamente en el origen y significación de aquello de donde nace, se avecine

nacimiento de Profeta Muhammad. La traducción de un bello pasaje del poema de Celebi figura en la Islamología del profesor Felix María Pareja, Madrid, 195254, Tomo II, pp. 699-701. Epítetos de Muhammad pueden verse también en la obra de Ibn Al-'Arabī y en Al-Gazzäī. Referente a este mismo tema de los epítetos de Muhammad, el profesor Míkel de Epalza publicó un substancioso estudio bajo el título de "Los nombres del Profeta en la Teología Musulmana", en Encuentro. Documentos para el entendimiento Islamo-cristiano, $\mathrm{n}^{\circ}$ 59-60, marzo-abril, 1967, que presenta gran interés tanto para teólogos musulmanes como cristianos y occidentales. 
y asemeje a cuyo es, cuanto es posible avecinarse a una cosa de tomo $y$ de ser el sonido de una palabra"s.

$$
* * *
$$

Dentro del pensamiento islámico, Al-Gazzālī explica el significado de los noventa y nueve nombres de Dios contenidos en la tradición de Muhammad, trasmitida por Abū Hurayra. De Al-Lāh dice que es el Nombre propio y exclusivo de Dios, que expresa su esencia en cuanto suma de todos sus atributos. Los atributos Ar-Rahmān y Ar-Rahīm significan para Al-Gazzālī la voluntad perfecta y universal de satisfacer todas las necesidades de dignos e indignos, tanto en ésta como en la otra vida. Hace la distinción entre Ar-Rahmān, el Misericordioso, que es cualidad exclusiva de Dios y se refiere propiamente a las gracias sobrenaturales, y Ar-Rahim, el Compasivo, que hace referencia a las gracias naturales. Fruto de ambos nombres para el místico son la misericordia para con los pecadores y compasión para con los pobres y desgraciados. Llega con ello a la explicación de cómo se concilia la misericordia divina con la existencia del malo .

De manera similar, el Šeij Tosun Bayrak Al-Ŷerrahi Al-Helveti en la compilación de los nombres de Dios, explica estos atributos. Referente a Al-Lah dice que es el Nombre más grande que contiene todos los bellos y divinos atributos y es el signo de la Esencia y la causa de toda existencia. Con el atributo Ar-Rahmān muestra Dios la misericordia y lo bueno para toda la creación, en todo momento, sin distinción entre los buenos y los malos, los fieles y los rebeldes, los amados y los odiados. Él derrama sobre la Creación una munificiencia

5 Fray Luis de León, Los nombres de Cristo, Obras Completas, B.A.C. Madrid, 1991. pp. 417-421.

${ }^{6}$ Cfr. Miguel Asín Palacios, El justo medio en la creencia. Compendio de Teología dogmática de Algazel. Instituto de Valencia de Don Juan, Madrid, 1929, pp. 437-438. Llama Al-Gazzāī esta parte de su tratado Libro del más sublime designio que explica el sentido de los bellísimos nombres de Dios. Explica en él los noventa y nueve nombres de Dios que D. Miguel Asin traduce y comenta. En nuestro pequeño trabajo, como orientación para el estudio del tema, nos limitaremos a tratar solamente de los nombres de Dios, $A l-L a h$, en árabe, y de los atributos Ar-Rạ̣mān y Ar-Rạịim. 
infinita cuya prueba encuentra en el Qur'ān, 7, 156: "Su misericordia abarca todo". Significa Ar-Rahìm que Dios es la Fuente de infinita misericordia y beneficencia y recompensa con regalos eternos a los que usan su munificencia para hacer el bien (Qur'ān, 33, 43: "Él es el Compasivo y el Beneficiente hacia los creyentes").

En cuanto a la porción del atributo divino que corresponde al hombre, viene dado por los apelativos de Siervos. 'Abd Al-Lāh es el Siervo que ha recibido el más alto nivel y honor que es posible alcanzar dentro de la Creación; este nombre pertenece solamente al Profeta Muhammad y a los Qutubs de cualquier tiempo, que son los verdaderos herederos de su sabiduría divina, puesto que Al-Lāh es el nombre de la Esencia de Al-Lāh, el Nombre más grande. 'Abd Ar-Rahmän, será aquél a quien Dios manifiesta su misericordia en el Universo. 'Abd ArRahìm, será la persona piadosa con un temor y amor a Dios constantes ${ }^{i}$.

'Abd Al-Razzāq Al-Qāshānī explicaba estos apelativos referidos a los Siervos de Dios. Decía que El Siervo de Dios, 'Abd Al-Lāh, es el hombre a quien la Verdad ha iluminado con todos sus Nombres, de manera que no hay devoto de la verdad que esté en un nivel más ensalzado. Realmente este nombre debería usarse solamente para el Profeta y para el Polo de cada Era que sobreviene, de entre los herederos de su descendencia, aunque otros hayan sido llamados alegóricamente Siervos de Dios. La característica de cada uno de los nombres de Dios es tomada en conjunto en todos los nombres de Dios en virtud de la unicidad y la unidad de todos los nombres.

En cuanto al Siervo del Compasivo, 'Abd Ar-Rahmān -dice AlQāshāni- resume el nombre del Compasivo y es una gracia para todo el mundo en general. De esta manera nadie que tenga la capacidad para esto queda excluido de su compasión. El siervo del Misericordioso, 'Abd Ar-Rahīm, ejemplifica el nombre del Misericordioso y otorga su merced especialmente al piadoso, al virtuoso y a aquéllos en quienes

${ }^{7}$ The most Beautiful Names compiled by Sheikh Tosun Bayrak al-Jerrahi alHelveti, Amana Books Brattleboro, Vermont, 1985, pp. 5-10. 
Dios se complace. Pero es vengativo para aquéllos con quienes Dios está airado ${ }^{8}$.

Referente al uso de estos atributos, como hemos esbozado al inicio de este estudio, es de gran valor la invocación frecuente a Al-Lāh (Qur'ān, 33, 41; 41, 42). También en Qur'ān, 20, 14, dice: "Ciertamente yo soy Dios. No hay Dios sino Yo. Por ello servidme y sed asiduos en la oración para recordarme". Y de los Nombres de Dios, dice: "A Dios pertenecen los más bellos nombres. Invocadle por sus nombres; pero alejaos de aquéllos que hacen mal uso de estos nombres" $(7,180)$.

Algunos estudiosos de los maestros orientales piensan que en Occidente el intelectual enseña que se debe comprender una cosa para obtener provecho de ella, mientras que la Tradición suff no se apoya en algo tan banal como esa habilidad superficial. La energfa sutil, la baraka, se filtra hacia adentro, a menudo a pesar de uno, en vez de esperar en el umbral de la puerta hasta que el "intelecto" le permita penetrar en una forma ya atenuada. Por ello explican que algunas veces hay ejercicios especificos para acompañar por ejemplo una lectura, que pueden tomar la forma de repetición de un texto que se está estudiando o de frases que sean dadas por el maestro.

Para conseguir mantener el contacto o la relación con Dios se utiliza el $\underline{d i k r}$. Este $\underline{d i k r}$ o recitación se utiliza, además de para repetir los Nombres de Dios, para repetir suras o versos del Qur'ān. Puede realizarse de manera pública, para ello debe repetirse el nombre o la fórmula un gran número de veces, o de manera particular, secreta, en cuyo caso debe mantenerse el nombre constantemente en los labios y en el corazón.

En general los místicos musulmanes están organizados en diversas

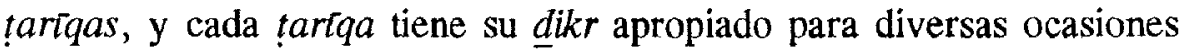
además de sus fórmulas y procedimientos especiales, sus letanías de

${ }^{8}$ A Glossary of Sufi Technical Terms compiled by "Abd al-Razzāq AlQäshänī. Texto árabe con traducción inglesa por el Dr. Nabil F. Safwat. The Octagon Press Ltd., Londres, 1991, pp. 91-92 ár./ 66 ingl. 
nombres y atributos divinos, sus diversas invocaciones y sus métodos de recitación modulada. Por ejemplo, en la tartqa mawlawiyya fundada por Ŷalāl Al-Dīn Rūmĩ, sus miembros, conocidos como los "derviches danzantes", giran durante el $d i k r$ al son de instrumentos.

Aunque el uso de cualquier nombre de Dios sirve, se suele seleccionar aquél cuya cualidad o característica representa más especificamente la necesidad que quiere tratar o atender; por ejemplo si se necesita guía se seleccionará el atributo o nombre $\mathrm{Al}-\mathrm{Ha} d \bar{d}, \mathrm{El}$ Gúa, ¡Yāà Hādī!, que repetirá el adepto un determinado número de veces.

Estos nombres, según la técnica empleada en la mística musulmana, deben ser dichos en árabe. La importancia del sonido y valor cadencial de estos ejercicios se debe a que están asociados a los ritmos respiratorios. Deben realizarse en el idioma original por el valor fonético del sonido, aunque el ejercicio se haga en silencio y no en voz alta, pues el valor del sonido está en la mente. Al repetir ese sonido, junto al conocimiento del significado, la mente está funcionando según esa cualidad o de la forma en que se manifiesta. De este modo, quien aspira a recibir la cualidad que necesite, desarrolla la relación con dicha cualidad y se familiariza con ella.

En la actualidad hombres religiosos utilizan el dikr para conseguir el conocimiento y contacto con la Realidad además de utilizar el mismo como moderna técnica empleada por terapeutas. Cuando pacientes con problemas psicológicos tratan o establecen una relación emocional con el terapeuta para usar esta conexión y abusar de ella, se recomienda que el terapeuta use un dikr para salir de una situación en donde se esté produciendo demasiada emoción. Pedirán la ayuda $\mathrm{y}$, mediante la repetición de un dikr adecuado para esta intención, podrán separarse del paciente en ese momento y de este modo salir de esa situación para volver de nuevo con corrección al contacto con el paciente.

Puede ser empleado incluso para operaciones de tratamiento de enfermedades. Para ello se habrá de repetir, ya sea en grupo, ya individualmente, el $\underline{d i k r}$ adecuado un número muy elevado de veces. Pues se supone que la relación entre la cosa deseada y la palabra es la de causa y efecto.

Si una persona, aconseja el Maestro Suff, tiene la dificultad acerca del conocimiento de Dios o desea sentir la mayor cercanía hacia Él 
puede valerse, para compensar esta carencia, de la lectura de libros y manuscritos de los grandes Maestros, porque de una u otra forma, directa o indirectamente, ayudan a la persona a desarrollar este enfoque personal sobre Dios, o bien se vale de los noventa y nueve Nombres o atributos de Dios, pues una persona que busca a Dios, progresivamente, va tomando conciencia de lo que para sí misma es Dios. Para acercarse a Él realmente, ha de realizar el intento de desarrollar una comprensión de la naturaleza de Dios.

$$
* * *
$$

\section{Los Nombres de Dios}

Ar-Rahmān: El Más Lleno de Gracia Ar-Rahīm: El Más Misericordioso Al-Malik: El Señor Soberano Al-Quddūs: El Santo

As-Salām: La Fuente de la Paz Al-Mu'min: El Guardián de Ia Fe Al-Muhaymin: El Protector Al-'Azīz: El Poderoso Al-Ŷabbār: El Impulsor Al-Mutakabbir: El Majestuoso Al-Jāliq: El Creador Al-Bāri': El Que Hace Evolucionar Al-Musawwir: El Modelador Al-Gaffār: El Indulgente Al-Qahhär: El Que Somete Al-Wahhāb: El Dador Ar-Razzāq: El Proveedor Al-Fattāh: El Que Abre Al-'Alim: El Omnisciente Al-Qäbid: El Constrictor Al-Bāsit: El Que Abastece Al-Jāfid: El Que Humilla Al-Rāfi': El Que Eleva Al-Mu'izz: El Que Da Honor Al-Mudill: El Que Quita Honor As-Samī': El Que Todo lo Oye Al-Basīr: El Que Todo lo Ve
Al-'Adl: El Justo

Al-Latīf: El Sutil

Al-Jabir: El Bien Informado

Al-Halim: El Clemente

Al-Azìm: El Grandioso

Al-Gafūr: El Que Perdona

Aš-Šakūr: El Que Agradece

Al-'Aliyy: El Altísimo

Al-Kabīr: El Grande

Al-Hafiz: El Guardián

Al-Muqit: El Que Sostiene

Al-Hasib: El Que Estima

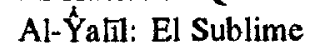

Al-Karīm: El Generoso

Ar-Raqiib: El Vigilante

Al-Muŷib: El Que Responde

Al-Wāsi': El Que Todo lo Abarca

Al-Hakim: El Sabio

Al-Wadūd: El Amoroso

Al-Maȳin: El Glorioso

Al-Bā'it: El Que Resucita

As-Šahīd: El Testigo

Al-Haqq: La Verdad

Al-Wakil: El Fiable

Al-Qawiyy: El Fuerte

Al-Matīn: El Firme

Al-Waliyy: El Amigo Protector 
Al-Hakam: El Juez

Al-Muhsii: El Que Tiene en Cuenta Al-Mubdi': El Que Da Origen

Al-Mu'îd: El Restaurador

Al-Muhiyy: El Dador de la Vida

Al-Mumit: El Creador de la Muerte

Al-Hayy: El Viviente

Al-Qayyūm: El Que Perdura por Sí Mism Al-Wāŷid: El Que Encuentra

Al-Māŷid: El Noble

Al-Wāhid: El Único

Al-Ahad: El Uno

As-Samad: El Eterno

Al-Qādir: El Capaz

Al-Muqtadir: El Todopoderoso

Al-Muqaddim: El Dispuesto

Al-Mu'ajjir: El Que Retrasa

Al-Awwal: El Primero

Al-Ājir: El Último

Az-Zāhir: El Evidente

Al-Bātin: El Oculto

Al-Wāri: El Gobernador

Al-Muta'ā̄̄ : El Más Enaltecido
Al-Hamīd: El Digno de Alabanza

Al-Barr: La Fuente de Toda Virtud

At-Tawwāb: El Apiadado

Al-Muntaqim: El Vengador

Al-'Afuww: El Que Perdona

Ar-Ra'ūf: El Compasivo

Mālik al-Mulk: El Señor del Universo

Dū-l-Ŷalāl wa-l-Ikrām: Señor de la Gracia y de la Nobleza

Al-Muqsit: El Equitativo

Al-Ŷāmi‘: El Que Congrega

Al-Ganiyy: El Rico

Al-Mugni: El Que Enriquece

Al-Māni‘: El Que Previene

Aḍ-Dărr: El Que Aflige

An-Nāfí: El Propicio

An-Nūr: La Luz

Al-Hădĩ: El Guía

Al-Badi": El Incomparable

Al-Bāqī: El Eterno

Al-Wārit: El Heredero Supremo

Ar-Rašì: El Guía del Camino Recto

Aș-Șabūr: El Paciente 